\title{
Injectable calcium phosphate foams for the delivery of Pitavastatin as osteogenic and
} angiogenic agent

Kanupriya Khurana $^{\mathrm{a}, \mathrm{b}, \mathrm{d}}$, Jordi Guillem-Marti ${ }^{\mathrm{a}, \mathrm{b}}$, Flavio Soldera ${ }^{\mathrm{d}}$, Frank Mücklich ${ }^{\mathrm{d}}$, Cristina Canal $^{\mathrm{a}, \mathrm{b}}$, Maria-Pau Ginebra ${ }^{\mathrm{a}, \mathrm{b}, \mathrm{c}, *}$

${ }^{a}$ Biomaterials, Biomechanics and Tissue Engineering Group, Dpt. Materials Science and Metallurgy, Universitat Politècnica de Catalunya (UPC), Av. Eduard Maristany 16, Barcelona, 08019, Spain

${ }^{\text {b} B a r c e l o n a ~ R e s e a r c h ~ C e n t e r ~ i n ~ M u l t i s c a l e ~ S c i e n c e ~ a n d ~ E n g i n e e r i n g, ~ U P C, ~ B a r c e l o n a, ~ S p a i n ~}$ 'Institute of Bioengineering of Catalonia (IBEC), Baldiri i Reixach 10-12, Barcelona, 08027, Spain

${ }^{\mathrm{d} C h a i r}$ of Functional Materials, Department of Materials Science and Engineering, Saarland University, Germany

*Corresponding author: Maria-Pau Ginebra

email: maria.pau.ginebra@upc.edu

Universitat Politècnica de Catalunya (UPC),

Av. Eduard Maristany 16, Barcelona, 08930, Spain

Tel: 0034934017706

\begin{abstract}
Apatitic bone cements have been used as a clinical bone substitutes and drug delivery vehicles for therapeutic agents in orthopedic applications. This has led to their combination with different drugs with known ability to foster bone formation. Recent studies have evaluated Simvastatin for its role in enhanced bone regeneration, but its lipophilicity hampers incorporation and release to and from the bone graft.

In this study, injectable calcium phosphate foams (i-CPF) based on $\alpha$-tricalcium phosphate were loaded for the first time with Pitavastatin. The stability of the drug in different conditions relevant to this study, the effect of the drug on the i-CPFs properties, the release profile, and the in vitro biological performance with regards to mineralization and vascularization were investigated. Pitavastatin did not cause any changes in neither the micro nor the macro structure of the i-CPFs, which retained their biomimetic features. PITA-loaded i-CPFs showed a dose-dependent drug release, with early stage release kinetics clearly affected by the evolving microstructure due to the setting of
\end{abstract}


cement. In vitro studies showed dose-dependent enhancement of mineralization and vascularization. Our findings contribute towards the design of controlled release with low drug dosing bone grafts: i-CPFs loaded with PITA as osteogenic and angiogenic agent.

Keywords: Controlled Drug Release; Vascularization; Mineralization; Rat Mesenchymal Stem Cells; Endothelial Progenitor Cells.

\section{Introduction}

Bone defects represent a major health burden, especially when they are of critical size and cannot heal following the usual regeneration mechanisms of bone [1]. In such cases bone grafting surgery is required, and in this context synthetic bone biomaterials have an increasing demand. Among the different biomaterials available, calcium phosphate cements (CPC) present several advantages that have fostered their study and application [2-4]. In particular, their composition mimicking the bone mineral phase, their ability to strongly bond with bone, their injectability and self-setting ability are some of their main assets [5-9]. Moreover, their intrinsic micro-nanoporosity makes them ideal candidates as drug delivery vehicles $[10,11]$, and have thus been studied in combination with different drugs including anti-inflammatories, antibiotics or anti-osteoporotic drugs [12-15].

Interconnected macroporosity is a key feature of synthetic bone grafts, since it allows circulation of nutrients and cell infiltration and enhances resorption and bone ingrowth. Moreover, when injectable CPCs are used as matrices for the delivery of drugs or active molecules, the presence of interconnected macropores has been shown to significantly enhance drug delivery [14]. So far, a number of methods have been investigated to obtain macroporous CPCs [16-21]. In this work we focus specifically on injectable calcium phosphate foams (i-CPF) obtained by foaming biocompatible surfactants. This method has been found adequate for obtaining stable scaffolds with interconnected macroporosity [17].

Statins are extensively used drugs, employed mainly as inhibitors for the cholesterol biosynthesis. Additionally, they are known to present several pleotropic effects, such as improving endothelial function, decreasing oxidative stress and inflammation, or 
inhibiting the thrombogenic response, among others [22]. Interestingly, Mundy et al. reported that they also played a role in bone formation, through the stimulation of Bone Morphogenetic Protein-2 (BMP-2) expression [23]. This led to a wide investigation, focusing especially on simvastatin (SIM), as a potential drug for bone regeneration [23, 24]. However, the hydrophobic nature of SIM results into low oral bioavailability ( $\leq 5 \%$ ), due to extensive first-pass metabolism in the gastro-intestinal wall and high extraction in the liver [25]. The hydrophobic nature of SIM also hampers its uniform incorporation in water-based matrices, as is the case of CPCs, which are formed by a combination of powder and aqueous liquid phase.

With the aim of fostering bioavailability and ease of incorporation in CPCs, a more hydrophilic statin, Pitavastatin (PITA) in combination with a macroporous CPC has been investigated for the first time in this work. Due to its higher oral absorption and oral bioavailability, PITA has a higher potency than SIM [26-28]. Additionally, its higher solubility provides a better platform for uniform incorporation to CPFs through the aqueous liquid phase. Moreover, although the studies on the pleiotropic effects of PITA are scarce [29], some findings suggest that it enhances bone turnover markers [30]; and gene expressions for mineralization [31].

The aim of this study is to explore the feasibility of incorporating PITA in i-CPFs as a strategy to foster the bone regenerative process at the defect site, using a lower dosage than SIM due to its higher potency. To this end, the effects of PITA on mesenchymal stem cells and on endothelial progenitor cells were evaluated, and the interactions of PITA with the physic-chemical properties of i-CPFs were assessed, together with its drug release properties from i-CPFs.

\section{Materials and methods}

\subsection{Pitavastatin stability}

Pitavastatin Calcium $\left(\mathrm{C}_{25} \mathrm{H}_{23} \mathrm{FNO}_{4} * 0.5 \mathrm{Ca} * 2 \mathrm{H}_{2} \mathrm{O}\right.$; Tocris Bioscience, UK) is a very slightly soluble compound in water, which was received in powder form and incorporated in the liquid phase. The molecular structure of PITA is shown in Fig. 1. In the evaluation of the stability of PITA, two main factors were taken into account: $\mathrm{pH}$ and temperature. The temperature stability was evaluated with solutions of PITA prepared in Phosphate Buffer Saline (PBS) at different concentrations (5, 50 and $100 \mu \mathrm{M})$ and stored at $5{ }^{\circ} \mathrm{C}$ and 373 
${ }^{\circ} \mathrm{C}$ with a $\mathrm{pH}$ of 6.5 . Similarly, PITA's stability was assessed at alkaline $\mathrm{pH}$ based on the fluctuations registered during cement setting; During the setting reaction of i-CPF the $\mathrm{pH}$ reaches alkaline values of $\mathrm{pH} 9.5$ and eventually shifts to neutral $\mathrm{pH} 7$ during the initial $24 \mathrm{~h}$ [32]. PITA was dissolved in water (5, 25, 50, 75 and $100 \mu \mathrm{M})$ and stored at $37{ }^{\circ} \mathrm{C}$. For the $\mathrm{pH}$ stability studies water was adjusted to $\mathrm{pH} 8$ and $\mathrm{pH} 9.5$ by addition of $0.01 \mathrm{M}$ $\mathrm{NaOH}$ and PITA solutions were subsequently prepared. The quantification of PITA solutions at various time points was carried out with High performance liquid chromatography (HPLC) in a Shimadzu HPLC system. A mobile phase of Acetonitrile: $0.1 \%$ phosphoric acid at a ratio of $50: 50(\mathrm{v} / \mathrm{v})$, at a flow rate of $0.5 \mathrm{ml} / \mathrm{min}$ was passed through a C8 column (Shim-pack, Shimadzu). An injection volume of $10 \mu \mathrm{L}$ of the release sample was measured by photodiode array (PDA) at $\lambda_{\max }=245 \mathrm{~nm}$. 3 replicates were analyzed for each condition.

\subsection{Evaluation of the effects of Pitavastatin on mesenchymal stem cells and} endothelial progenitor cells in vitro

The osteogenic and angiogenic effects of PITA were evaluated in vitro with rat Mesenchymal stem cells (rMSCs) and endothelial progenitor cells (EPCs) respectively. Both cell types were extracted from femurs of young Lewis rats at the Institute for Bioengineering of Catalonia (IBEC), as in previous works [33]. Cell phenotypes were previously characterized by flow cytometry [34]. rMSCs cells were expanded in Advanced DMEM supplemented with 10\% fetal bovine serum (FBS), 20 mM HEPES buffer solution, penicillin/streptomycin antibiotics (50 U/ml and $50 \mu \mathrm{g} / \mathrm{ml}$, respectively), and 2 mM L-glutamine (all from Invitrogen) at $37^{\circ} \mathrm{C}$ with $5 \% \mathrm{CO}_{2}$ and $95 \%$ relative humidity. On the other hand, supernatant containing EPCs were centrifuged and re-suspended in EBM medium (Lonza) supplemented with EGM-2 BulletKit and 5\% FBS. Both cell types were used from passage 4 for all the experiments. $10^{4}$ cells/well were seeded in 24 well plates and cultured in their corresponding medium with PITA $(0.1,1$ and $10 \mu \mathrm{M})$ and Tissue culture polystyrene (TCPS) was used as control. PITA was received in powder form and used as received to prepare a stock solution in MilliQ water, which was further diluted to the final concentration of $0.1,1$ and $10 \mu \mathrm{M}$ in cell culture medium.

The expression of osteogenic marker genes in rMSCs (BMP-2, Osteocalcin, Collagen-I) and vascularization genes in rEPCs (VEGFA, VEGFR-1, VEGFR-2) was determined through RT- 
qPCR assay at various time points (6 and 24h, 3 and 7 days). The DNA primer sequences are detailed in Table 1. A detailed protocol and calculations have been described elsewhere [35]. Briefly, at each culture time, total RNA was extracted using RNeasy®Mini Kit (Qiagen, Hilden, Germany) and quantified using a NanoDrop ND-1000 spectrophotometer (NanoDrop Technologies, Montchanin, DE, USA). RNA (200 ng) was retrotranscribed to cDNA using the QuantiTect Reverse Transcription Kit (Qiagen) and retrotranscribed to cDNA using the QuantiTect SYBR Green RT-PCR Kit (Qiagen) in a StepOnePlus Real-Time PCR System (Applied Biosystems, Foster City, CA, USA). The fold change for each gene expression was obtained after normalizing the values to TCPS at $6 \mathrm{~h}$ and to $\beta$-actin.

\subsection{Preparation of Pitavastatin loaded injectable calcium phosphate foams}

$\alpha$-TCP was used as a solid phase of i-CPFs and was obtained as described elsewhere [14]. 2 wt.\% of precipitated hydroxyapatite (HA; BP-E341, Merck, Germany) was added as a seed in the powder. $10 \mathrm{wt} \%$ Pluronic F-127 (Sigma Aldrich, USA) was blended with the solid phase for the preparation of the i-CPFs. The liquid phase was a solution of 1 wt\% of Polysorbate 80, herein Tween80 (Polysorbate 80, Sigma Aldrich, USA) in distilled water. PITA solutions were prepared at 50, 75, 100 and $200 \mu \mathrm{M}$ by incorporating it in the liquid phase.

Self-setting i-CPFs were foamed by mixing the solid and the liquid phase at a liquid-topowder ratio of 0.55 at $7000 \mathrm{rpm}$ for $30 \mathrm{~s}$ using a domestic hand mixer. The foams were injected in Teflon cylindrical moulds of $6 \mathrm{~mm}$ x $12 \mathrm{~mm}$ and left to consolidate in $100 \%$ relative humidity at $37 \stackrel{\circ}{\circ}$, followed by immersion in water at $37^{\circ} \mathrm{C}$ for 7 days to allow for complete reaction, prior to physic-chemical characterization.

\subsection{Physico-chemical characterization of i-CPFs}

The microstructure of a fracture region of the i-CPFs was characterized by field emission scanning electron microscopy (FESEM) (Neon 40, Zeiss, Germany) at $10 \mathrm{kV}$ working voltage. Prior to observation, samples were Au-sputter coated (K950X, Emitech, US). The Specific Surface Area (SSA) of i-CPFs was measured by Nitrogen adsorption in an ASAP 2020 (Micromeritics) with 6 cylindrical samples, using the Brunauer-EmmetTeller (BET) method.

Helium pycnometry (AccuPyc 1330, Micromeritics, USA) was used to measure the 
skeletal density of i-CPFs and i-CPFs with $100 \mu \mathrm{M}$ PITA with four cylindrical samples. Mercury intrusion porosimetry (MIP, AutoPore IV, Micrometrics, USA) was performed to determine the pore entrance size distribution (PESD) within the materials. Four cylindrical samples were introduced in the sample holder for the measurement, and a single measurement was performed for each composition.

\subsection{Micro-computed tomography}

A 3-dimensional micro-computed (3D micro-CT) system TOMOLIBRIR developed at the FRAUNHOFER IZFP Saarbrucken, Germany was used to evaluate the threedimensional (3-D) morphology of CPFs. The scanner was operated to obtain a voxel size of $4^{3} \mu^{3}$, at $100 \mathrm{kV}$ and $9 \mathrm{~W} \mathrm{X}$-ray power with a data acquisition and reconstruction software, Volex. The samples employed were cylinders with $6 \mathrm{~mm}$ in diameter and 12 mm height. The 3-D volume was then reconstructed using the software Amira network (version 5.4.3).

\subsection{Evaluation of Pitavastatin release}

For drug release studies, i-CPFs were prepared with the liquid phase containing PITA at different concentrations (50, 75, 100 and $200 \mu \mathrm{M}$ ) as described in Section 2.3. They were injected in $2 \mathrm{~mm}$ x $6 \mathrm{~mm}$ Teflon molds adapted from the United States Pharmacopoeia (USP) ointment cell with only one open side allowing contact with the release medium. Prior to release, they were kept for $5 \mathrm{~h}$ in $100 \%$ relative humidity to have sufficient cohesion. The total amount of PITA loaded per sample was calculated from equation 1 by weighing each i-CPF $\left(W_{i-C P F}^{T O T A L}\right)$ before release and employing the concentration of PITA in the liquid phase, as well as the weight (W) of solid phase and liquid phase employed to prepare the i-CPF formulation:

$W_{i-C P F}^{P I T A}=\frac{W_{\text {Liquid phase }}^{\text {PITA }}}{W_{\text {Liquid phase }}^{\text {PITA }}+W_{\text {Solid phase }}+W_{\text {Liquid phase }}} \times W_{i-C P F}^{T O T A L}$

Release studies were then conducted for 6 days by immersing the i-CPFs moulds in $5 \mathrm{~mL}$ of Phosphate Buffer Saline (PBS, $\mathrm{pH}=7.4$ ) at 37으 $\mathrm{C}$ with continuous stirring of $100 \mathrm{rpm}$. At each time point $350 \mu \mathrm{L}$ of release medium was withdrawn and replaced with $350 \mu \mathrm{L}$ of fresh PBS. The amount of drug released was quantified by measuring the concentration of PITA in the release media collected at each time point with HPLC following the 
protocol described in the previous section. The cumulative release was plotted as a function of time after correcting the data for evaporation of PBS during 6 days. Additionally, the data for total percentage of PITA released was corrected for degradation occurred during setting. Modelling was performed using the Korsmeyer-Peppas (KP) model. The variable fitted is the quantity released at time $t\left(\mathrm{M}_{\mathrm{t}}\right)$, normalized by the maximum quantity released $\mathrm{M}_{\infty}$ (Eq. (2)):

$$
\mathrm{M}_{\mathrm{t}}=\mathrm{M}_{\infty} \cdot \mathrm{k} \cdot \mathrm{t}^{\mathrm{n}}
$$

where $\mathrm{k}$ is a constant that accounts for structural parameters of the material and characteristics of the active principle such as the effective coefficient of diffusion. The exponent $\mathrm{n}$ allows the identification of the mechanism controlling the release. Specifically, for a given geometry of the sample it allows discerning between a release controlled by Fickian diffusion, swelling/case II transport or an Intermediate situation. The KP model is applicable only up to $60 \%$ of the quantity released. The exponent $n$ describes the shape of the curve. The quantity released as a function of time was thus fitted with the KP equation, and both the value of the exponent $n$ and the correlation coefficient $\mathrm{R}^{2}$ were reported.

\subsection{Statistics}

Statistical differences were determined using one-way ANOVA with Tukey's post hoc tests using minitab software. Statistical significance was considered when $\mathrm{P}<0.05$. Data are presented as mean \pm standard deviation.

\section{Results}

\subsection{Stability of PITA}

Assessment of the stability of PITA at different temperatures is relevant in views of storage $\left(5^{\circ} \mathrm{C}\right)$ and drug release experiments $\left(37^{\circ} \mathrm{C}\right)$, while $\mathrm{pH}$ stability is important with views on its incorporation to CPCs. This is reported in Figure 2 up to 9 days. It was found that PITA in PBS was stable at both 5 and $37^{\circ} \mathrm{C}$ (Fig. 2, top), as no degradation was detected (P $>0.05$ ), allowing to perform the drug release assays at $37^{\circ} \mathrm{C}$ without risk of degradation of PITA, and if required, samples could be stored in the fridge. In contrast, it was observed 7 
that PITA was degraded at basic pH (Fig. 2, bottom), particularly at high concentrations of 50, 75 and $100 \mu \mathrm{M}$. The degradation was found to be similar at $\mathrm{pH} 8$ or 9.5 , and the amount degraded in the solutions corresponds to $\sim 8 \%$ in the first $24 \mathrm{~h}$ calculated with equation (3). The estimated degradation of PITA during i-CPF setting according to the setting $\mathrm{pH}$ of CPCs determined in previous works [32] was calculated with the following reaction, further explained in discussion section (eq. 3):

$\%$ Degradation $_{24 h}^{\text {PITA }}=\left(\frac{\text { Degradation }(\mathrm{pH} \mathrm{9.5)}}{24 \mathrm{~h}} \times 15 \mathrm{~h}\right)+\left(\frac{\text { Degradation }(\mathrm{pH} 8)}{24 \mathrm{~h}} \times 9 \mathrm{~h}\right)$

The degradation of PITA at $\mathrm{pH} 8$ and $\mathrm{pH} 9.5$ has been calculated as a function of time for the initial $24 \mathrm{~h}$ (Table 2).

3.2. Effects of Pitavastatin on mesenchymal stem cells and endothelial progenitor cells in vitro

The potential effects of PITA on the expression of some genes involved in bone regeneration were evaluated through RT-qPCR studies. The relative fold change in the expression by rMSCs of some osteogenic marker genes, namely Osteocalcin (OCN), collagen type 1 (Col type 1) and Bone Morphogenetic Protein-2 (BMP-2) is shown in Fig. 3, left column. An overexpression of OCN was observed in presence of PITA at 72h, which was more marked for the $0.1 \mu \mathrm{M}$ dose. This concentration led also to an overexpression of OCN at early time points (6 and 24h) and to a significant increase in both Col type 1 gene expression at $72 \mathrm{~h}$ compared to control, whereas no significant effect was observed for $1 \mu \mathrm{M}$ PITA. On the other hand, BMP-2 gene expression was observed to decrease with progressing time yet it was significantly higher for both $0.1 \mu \mathrm{M}$ and 1 $\mu \mathrm{M}$ PITA compared to the control at $72 \mathrm{~h}$.

Concerning EPCs, the gene expression of VEGFA, VEGF-R1, and VEGF-R2 were studied as an indication of the effect of PITA on vascularization, and the results are shown in the right column of Fig. 3. For the initial hours of 6, 24 and 48 h, in general PITA showed lower expression for vascularization factors than the control. Then, $0.1 \mu \mathrm{M}$ PITA induced an overexpression of VEGF-R1, VEGF-R2 and VEGFA at 72h compared to control. In contrast, PITA at $1 \mu \mathrm{M}$ produced a very significant decrease on the expression of the three genes (VEGFA, VEGF-R1 and VEGF-R2) at 72h. 


\subsection{Synthesis and characterization of PITA loaded i-CPFs}

PITA loaded i-CPFs were synthesized and their physic-chemical properties were evaluated as shown in Fig. 4 and Table 3. The i-CPFs showed level 3 cohesion [36] which remained unchanged with the PITA-loading. The characterization of the microstructure was conducted with control i-CPF and PITA loaded i-CPF $(100 \mu \mathrm{M})$, the highest concentration evaluated in the stability studies. The microstructure of the materials with and without PITA $(100 \mu \mathrm{M})$ in the bulk of i-CPFs, both displayed similar features. Entangled plate-like crystals derived from the dissolution-precipitation of $\alpha$-TCP responsible for cement hardening were observed in the control as well as in the PITA loaded i-CPFs. The drug was completely solubilized in the liquid phase and CDHA was formed as a result of the hydrolysis of the initial solid phase $\alpha$-TCP in i-CPFs. The reconstruction of the $\mu \mathrm{CT}$ scans allowed visualizing homogeneously distributed and interconnected porosity in i-CPFs with or without PITA as shown in Fig. 4 (bottom).

Additionally, specific surface area (SSA), skeletal density and total porosity measured through MIP showed no significant differences due to the presence of the drug, as reflected in Table 3 and Fig. 5.

\subsection{Pitavastatin release}

The evaluation of the PITA release kinetics from i-CPFs was evaluated for different concentrations of drug added to the liquid phase of i-CPFs (50 $\mu \mathrm{M}$ (50-PITA), $75 \mu \mathrm{M}$ (75PITA), $100 \mu \mathrm{M}$ (100-PITA) and $200 \mu \mathrm{M}$ (200-PITA)) in PBS for 6 days (Fig. 6). The cumulative release of PITA showed two different phases. Initially, a burst release was recorded in the first $5 \mathrm{~h}$, followed by a slow progressive release up to $72 \mathrm{~h}$, which later showed a tendency of stabilization. The release amount shows a dose dependent behavior from the initial time points as shown in the amplified image (Fig. 6 b), which is kept until the final amount released (Fig. 6 c).

200-PITA was the i-CPF showing the highest amount of PITA released (Fig. 6 a) which accounted only for $40.9 \pm 9.1 \%$ of the PITA loaded in the sample. Fitting parameters to the KP model useful to interpret the release kinetics of the i-CPFs are reported in Table 4.

\section{Discussion}


Many studies have reported the benefits of statins, especially SIM, on bone formation as well as on the inhibition of bone resorption [23, 27, 29, 37, 38]. Within the family of statins, PITA presents some interesting properties, in particular its lower price, hydrophilic properties and its comparable efficiency compared to other statins (i.e. SIM) at much lower concentrations. Therefore, PITA has potential advantages in views of fostering bone regeneration in combination with bone substitutes. However, to the best of our knowledge, the combination of PITA with bone bioceramics as drug delivery vehicles is still unexplored. In this work we addressed some aspects that are relevant for this application, namely, the stability of PITA under different conditions, its biological effects on MSCs and EPCs in vitro, and the feasibility of incorporating it in i-CPFs, including the effect of the molecule on the properties of the calcium phosphate foams and the release kinetics of the drug.

PITA solutions in PBS were stable both at 5 and $37^{\circ} \mathrm{C}$ for 9 days, which is interesting with regard to potential storage of samples, and also in views of the experimental conditions during cell cultures and release experiments.

The setting of calcium phosphate foams involves a dissolution-precipitation reaction, which entails a $\mathrm{pH}$ fluctuation. The dissolution of $\alpha$-TCP initially increases the $\mathrm{pH}$ of the liquid medium, up to $\mathrm{pH}=9.5$, slowly decreasing to $\mathrm{pH}=8$ in $24 \mathrm{~h}$ [32]. Therefore, the initial $24 \mathrm{~h}$ of the setting reaction act as an alkaline environment for PITA. To evaluate whether this high $\mathrm{pH}$ range could affect the stability of PITA, different PITA concentrations were exposed to alkaline $\mathrm{pH}$ of either 8 or 9.5 (Fig. 2). No degradation was found for the 5 and $25 \mu \mathrm{M}$ PITA solution over 9 days of exposure. In contrast, at higher concentrations of 50, 75 and $100 \mu \mathrm{M}$, a significant degradation was recorded which increased with exposure time at both pHs. This implies that there will be a partial degradation of PITA due to the $\mathrm{pH}$ fluctuations during the setting reactions. To estimate the extent of this degradation, we can assume that, according to previous studies that assessed the $\mathrm{pH}$ evolution during the setting reaction [32, 39], when PITA is mixed with an i-CPF, it will be exposed to a $\mathrm{pH} \leq 9.5$ for the initial $15 \mathrm{~h}$, and to a $\mathrm{pH} \leq 8$ during the following 9h. With this in mind, the degradation associated to the $\mathrm{pH}$ fluctuations during the setting reaction for $24 \mathrm{~h}$ was calculated as shown in equation (3), yielding $8 \%$ of degradation. This value was used for the correction of the final percentage of PITA released from the i-CPFs. 
Statins are described to promote in vitro angiogenesis and osteogenesis in a dose dependent manner [31, 40-43]. However, few studies have been conducted with PITA to demonstrate such effects. The present work was originally designed for three different concentrations of $0.1,1$ and $10 \mu \mathrm{M}$. It was found that $10 \mu \mathrm{M}$ resulted in toxic effects on the cell culture with complete loss of cell viability in rMSCs and EPCs. Therefore, the study was continued with concentrations of PITA in the cell culture medium of $0.1 \mu \mathrm{M}$ (0.0475 $\mu \mathrm{g} / \mathrm{mL})$ and $1 \mu \mathrm{M}(0.475 \mu \mathrm{g} / \mathrm{mL})$ (Fig. 3). The results showed an overexpression of genes associated to osteogenesis and vascularization with the lowest dosage of PITA $(0.1 \mu \mathrm{M})$. Our findings of OCN and BMP-2 overexpression are in agreement with other studies where the bone anabolic effect of PITA was reported to stimulate OCN by inhibition of Rho-associated kinase and BMP-2 in human osteoblasts [31] and collagen [30]. The present study observed similar results at $72 \mathrm{~h}$ with a concentration of $0.1 \mu \mathrm{M}$ in rMSCs whereas a previous work [31] reported overexpression at $48 \mathrm{~h}$ with $1 \mu \mathrm{M}$ in human osteoblasts. This difference can be explained as the concentration may depend on the type of cells, as seen earlier in other studies with simvastatin and other statins [4447]. Our results indicate that PITA induces mineralization, differentiation and osteogenesis in rMSCs.

In the case of EPCs, gene expression values for VEGF, VEGF-R1 and VEGF-R2 were followed for their key role in angiogenesis. VEGFA plays an important role as key regulator to promote growth of vascular endothelial cells and vessel growth, therefore an important marker for angiogenesis [48]. VEGFA binds to two receptors including VEGF-R1 and VEGF-R2. It has been seen that role of VEGF-R1 is still not well defined as it is known as a 'decoy' receptor which regulates VEGFA in a negative fashion by interfering with binding between VEGFA and VEGF-R2 [49]. On the other hand, recent studies claimed that VEGF-R1 plays a role in recruitment of endothelial progenitors [50]. Therefore, role of VEGF-R1 is still under debate. Though, VEGF-R2 plays a key role in angiogenesis by enhancing effects of VEGFA by binding with it [51]. In the present work, a significant increase was observed in VEGFA, VEGF-R2 and VEGF-R1 at $72 \mathrm{~h}$ suggesting stimulation of vascularization by PITA at $0.1 \mu \mathrm{M}$. It is important to take into account that the increase in VEGF-R2 was three fold with respect to the control, which is really essential for binding with VEGFA and stimulating angiogenesis. Similarly, PITA [52] and other statins [41, 53, 54] have been previously described to 
promote angiogenesis. Collectively, our data suggest that PITA has bone anabolic effects on both rMSCs and rEPCs, coping well with other studies, where $0.1 \mu \mathrm{M}$ was also found to be the most effective dose $[31,43]$.

In addition to the bone anabolic effects just discussed, PITA being a hydrophilic molecule allows direct dissolution in the aqueous liquid medium used for i-CPFs synthesis. This is an advantage, as other statins such as SIM require an additional step to convert it from hydrophobic to hydrophilic by lactone ring opening, if solubility in an aqueous phase is desired [55]. In contrast, PITA can be directly incorporated in the aqueous phase of the self-setting foams to have a homogenous distribution throughout the foam volume, which can facilitate a sustained and a prolonged release. Drug incorporation in self-setting cements and foams can often result in the modification of the setting times or alteration of the texture or porosity, among other parameters $[14,56$, 57]. Therefore, characterization of macroporous i-CPFs was conducted for 100-PITA samples. The i-CPFs displayed full conversion to calcium-deficient hydroxyapatite after setting, both with and without PITA (Supplementary Figure). As shown in the SEM images (Fig. 4), it was found that PITA did not induce observable changes in the microstructure of the set i-CPFs nor in the cohesion of the foamed pastes before setting. Similarly, MIP pore size entry distribution was found to be similar in both i-CPF and PITA loaded i-CPF (Fig. 6). SEM images showed plate like crystallites characteristic of the setting of $\alpha$-TCP to calcium-deficient hydroxyapatite [58]. Also, reconstruction from the $\mu \mathrm{CT}$ scans allowed visualization of interconnected macropores. The interconnected pores were seen clearly for control i-CPF as well as PITA (100 $\mu \mathrm{M})$ loaded i-CPF. The skeletal density, total porosity and specific surface area were in accordance with previous results and displayed no significant differences among control i-CPF and PITA loaded i$\mathrm{CPF}$ at $100 \mu \mathrm{M}$. These findings were in agreement with other studies for statins, where they showed that SIM did not alter phase composition or porosity of cements [59].

It has been shown that $0.1 \mu \mathrm{M}$ concentration can foster the expression of angiogenic and mineralization genes. Despite this, a much higher concentration of PITA was loaded in the i-CPFs. This was done with two considerations in mind: 1) the degradation of the drug due to the setting reaction (Table 2) that can be assumed to "inactivate" a 6.5-8 \% of the PITA incorporated in i-CPFs (as seen for 50, 75 and $100 \mu \mathrm{M}$ ) during the period of time in which the setting proceeds at basic pHs between 8 and 9.5; and 2) in our release 
assays, having a detectable concentration of PITA had to be ensured (below $1 \mu \mathrm{M}$ it was undetectable). Moreover, studying the release behavior of i-CPFs (Fig. 5) prepared at different concentrations may allow extrapolating it to adjust to the desired concentration in future.

The initial burst release recorded was in agreement with other findings showing freshly prepared CPCs or pre-set CPCs set for short times which also display burst release [59]. The Korsmeyer-Peppas model was fitted to analyze the release kinetics (Table 4) but did not allow any conclusion as the parameter (n) was too low for the case of release from flat surfaces. On the other hand, some studies based on matrix tablets have shown that a value lower than $n<4.5$ reflects a quasi-Fickian diffusion behavior [60, 61]. The profiles obtained can be ascribed to the evolving microstructure of the cement setting, which is responsible for the change in the elution regimes. Initially, the paste is just a suspension of $\alpha$-TCP particles in aqueous solutions of PITA. As $\alpha$-TCP precipitates to CDHA following the cement setting reaction, the network of CDHA crystals created progressively increases tortuosity, hindering the drug diffusion and reducing the release rate [59].

It has been observed that 50-PITA i-CPFs released $0.2 \mu \mathrm{g} / \mathrm{mL}$ which is very high in comparison to the $0.1 \mu \mathrm{M}$ concentration shown to be effective in vitro. It is important to keep in account that release studies were designed with the aim of being within the detection range $(1 \mu \mathrm{M})$ of HPLC technique for PITA. However, if we extrapolate the release values obtained at different concentrations we can estimate that a lower loading of PITA (5-10 $\mu \mathrm{M})$ in iCPFs, will lead to a release around the $0.1 \mu \mathrm{M}$ shown useful in vitro.

When comparing the present findings with our previous work on simvastatin loaded scaffolds [62]: a) PITA shows a much higher loading efficiency due to its higher solubility than simvastatin, which gives an edge for incorporation of PITA through liquid phase b) Percentages released are much higher ( 97 - $40 \%$ PITA vs. $16 \%$ Simvastatin), and progressive, which can be explained by the fact that i-CPFs are evolving matrices, with a high amount of liquid phase where PITA is dissolved, so in the initial release timeframe, exchange with the release media is much more favoured than with the set macroporous CDHA samples employed in previous works [62]. Moreover, PITA is efficient in vitro at lower dosages [63] so the progressive release behavior might allow to maximize the efficiency of the treatment.

Different release profiles are reported in the literature for SIM with different calcium 
phosphates: premixed cements [64] and CDHA cements and sintered ceramics [60, 62, 65]; However, it is the first time that PITA has been loaded within a calcium phosphate. The iCPFs presented in this study exhibit a progressive release profile, corresponding to $\sim 40 \%$ of the quantity loaded in 200-PITA and almost 97\% released for 50-PITA and 75-PITA. The interconnected macroporosity (Fig. 6b) of all these samples is expected to enhance, in addition, tissue colonization. The release profile of all samples stabilized after $72 \mathrm{~h}$ wherein probably a significant amount of $\alpha$-TCP had transformed already to CDHA, hindering the diffusion of the drug trapped within the crystal structure, as reflected in Fig. 6.

Moreover, the macroporosity of the i-CPFs investigated can be assumed to foster higher amounts of drug released to the media, in comparison with their non-macroporous homologues, as fluid exchange is fostered in this kind of samples with respect to dense cements [14].

\section{Conclusions}

Pitavastatin was evaluated combined with i-CPFs as potential bone regeneration enhancer. First, PITA shows a stable behaviour in PBS at different working temperatures of $37^{\circ} \mathrm{C}$ (important in i-CPFs preparation and in release studies) and of $5{ }^{\circ} \mathrm{C}$ (relevant for its storage in solution), but a certain degradation (8\%) was recorded in the setting conditions of the cements, so this should be taken into account when formulating the i-CPF dosage form. Second, i-CPFs and PITA loaded i-CPFs both exhibited similar interconnected macroporous structure with no significant changes in microstructure (Plate like crystallites), SSA, total porosity, pore size distribution or skeletal density. Third, $0.1 \mu \mathrm{M}$ concentration of PITA resulted in the enhancement of gene expressions of OCN, collagen type 1 and BMP-2 in rMSCs indicating towards mineralization and differentiation. In the case of EPCs, gene expressions of VEGFA, VEGF-R2, and VEGF-R1 were enhanced by 72h as verified by RTPCR indicative of angiogenesis. Finally, PITA loaded i-CPFs followed release kinetics according to the evolving microstructure of the foamed cement in the initial hours, with a burst release which slowly progressed to a slower release in a dose-dependent manner. Design of the i-CPFs as a drug delivery system loaded with PITA, an osteogenic and angiogenic promoter, allowing very low dosages, with the fact that it does not alter the attractive biomimetic features of the i-CPFs studied here makes them a captivating 
alternative for versatile bone grafts.

\section{Acknowledgements}

Authors acknowledge the Spanish Government for financial support through Project MAT2015-65601-R, co-funded by the EU through European Regional Development Funds, and Ramon y Cajal fellowship of Cristina Canal. Support for the research of Maria Pau Ginebra was received through the "ICREA Academia" prize for excellence in research, funded by the Generalitat de Catalunya. The European Union is acknowledged for the DocMASE PhD scholarship of Kanupriya Khurana.

The authors thank Dr.-Ing. Michael Maisl for kindly allowing access to the $\mu \mathrm{CT}$ instrument at the Fraunhofer Institute for Nondestructive Testing (IZFP), Saarbrücken, Germany.

\section{References}

[1] P.P. Spicer, J.D. Kretlow, S. Young, J.A. Jansen, F.K. Kasper, A.G. Mikos, Evaluation of bone regeneration using the rat critical size calvarial defect, Nat. Protoc. 2012; 7; 1918-1929.

[2] W. Brown, L. Chow, A new calcium-phosphate setting cement, J. Dent. Res. 1983; 62; $672-672$.

[3] R.Z. LeGeros, Calcium phosphate-based osteoinductive materials., Chem. Rev. 2008; $108 ; 4742-53$.

[4] M.P. Ginebra, M. Espanol, E.B. Montufar, R.A. Perez, G. Mestres, New processing approaches in calcium phosphate cements and their applications in regenerative medicine., Acta Biomater. 2010; 6; 2863-73.

[5] S. V Dorozhkin, Calcium orthophosphate cements for biomedical application, J. Mater. Sci. 2008; 43; 3028-3057.

[6] M. Bohner, Calcium orthophosphates in medicine: from ceramics to calcium phosphate cements, Injury. 2000; 31 D37-D47.

[7] S. Deb, Orthopaedic bone cements, 2008; Woodhead Publishing.

[8] M. Bohner, U. Gbureck, J.E. Barralet, Technological issues for the development of 
more efficient calcium phosphate bone cements: A critical assessment, Biomaterials. 2005; 26; 6423-6429.

[9] M. Bohner, L. Galea, N. Doebelin, Calcium phosphate bone graft substitutes: Failures and hopes, J. Eur. Ceram. Soc. 2012; 32; 2663-2671.

[10] M. Espanol, R.A. Perez, E.B. Montufar, C. Marichal, A. Sacco, M.P. Ginebra, Intrinsic porosity of calcium phosphate cements and its significance for drug delivery and tissue engineering applications., Acta Biomater. 2009; 5; 2752-62.

[11]D. Pastorino, C. Canal, M.-P. Ginebra, Multiple characterization study on porosity and pore structure of calcium phosphate cements, Acta Biomater. 2015; 28; 205-214.

[12] M.-P. Ginebra, T. Traykova, J.A. Planell, Calcium phosphate cements: competitive drug carriers for the musculoskeletal system?, Biomaterials. 2006; 27; 2171-7.

[13]E. Verron, I. Khairoun, J. Guicheux, J.-M. Bouler, Calcium phosphate biomaterials as bone drug delivery systems: a review., Drug Discov. Today. 2010; 15; 547-52.

[14]D. Pastorino, C. Canal, M.-P. Ginebra, Drug delivery from injectable calcium phosphate foams by tailoring the macroporosity-drug interaction., Acta Biomater. 2015; 12; 250-9.

[15] M.-P. Ginebra, C. Canal, M. Espanol, D. Pastorino, E.B. Montufar, Calcium phosphate cements as drug delivery materials., Adv. Drug Deliv. Rev. 2012; 64; 1090-110.

[16] A. Almirall, G. Larrecq, J. Delgado, S. Martínez, J. Planell, M. Ginebra, Fabrication of low temperature macroporous hydroxyapatite scaffolds by foaming and hydrolysis of an $\alpha$-TCP paste, Biomaterials. 2004; 25; 3671-3680.

[17]E.B. Montufar, T. Traykova, C. Gil, I. Harr, A. Almirall, A. Aguirre, E. Engel, J.A. Planell, M.P. Ginebra, Foamed surfactant solution as a template for self-setting injectable hydroxyapatite scaffolds for bone regeneration., Acta Biomater. 2010; 6; 876-85.

[18]R.A. Perez, H.-W. Kim, M.-P. Ginebra, Polymeric additives to enhance the functional properties of calcium phosphate cements., J. Tissue Eng. 2012; 3; 2041731412439555.

[19] R.P. del Real, E. Ooms, J.G.C. Wolke, M. Vallet-Regí, J.A. Jansen, In vivo bone response to porous calcium phosphate cement, J. Biomed. Mater. Res. Part A. 2003; 65; 30-36.

[20]S. del Valle, N. Miño, F. Muñoz, A. González, J.A. Planell, M.-P. Ginebra, In vivo evaluation of an injectable Macroporous Calcium Phosphate Cement, J. Mater. Sci. Mater. Med. 2007; 18; 353-361. 
[21]S. Takagi, L.C. Chow, Formation of macropores in calcium phosphate cement implants, J. Mater. Sci. Mater. Med. 2001; 12; 135-139.

[22] J.K. Liao, U. Laufs, Pleiotropic effects of statins., Annu. Rev. Pharmacol. Toxicol. 2005; 45; 89-118.

[23] G. Mundy, Stimulation of Bone Formation in Vitro and in Rodents by Statins, Science 1999; 286; 1946-1949.

[24]I. Garrett, G. Gutierrez, G. Mundy, Statins and Bone Formation., Curr. Pharm. Des. 2001;7; 715-736.

[25] S. Vickers, C.A. Duncan, I.W. Chen, A. Rosegay, D.E. Duggan, Metabolic disposition studies on simvastatin, a cholesterol-lowering prodrug., Drug Metab. Dispos. 1990; 18; 138-45.

[26]R.Y.A. Mukhtar, J. Reid, J.P.D. Reckless, Drug focus, Int. J. Clin. Pract. 2005; 59; 239252.

[27]N. Horiuchi, T. Maeda, Statins and bone metabolism., Oral Dis. 2006; 12; 85-101.

[28]Y. Saito, Pitavastatin: an overview., Atheroscler. Suppl. 2011;12; 271-6.

[29] Y. Zhang, A.D. Bradley, D. Wang, R.A. Reinhardt, Statins, bone metabolism and treatment of bone catabolic diseases., Pharmacol. Res.; 2014.

[30]T. Majima, A. Shimatsu, Y. Komatsu, N. Satoh, A. Fukao, K. Ninomiya, T. Matsumura, K. Nakao, Short-term effects of pitavastatin on biochemical markers of bone turnover in patients with hypercholesterolemia., Intern. Med. 2007; 46; 1967-1973.

[31] K. Ohnaka, S. Shimoda, H. Nawata, H. Shimokawa, K. Kaibuchi, Y. Iwamoto, R. Takayanagi, Pitavastatin Enhanced BMP-2 and Osteocalcin Expression by Inhibition of Rho-Associated Kinase in Human Osteoblasts, Biochem. Biophys. Res. Commun. 2001; 287; 337-342.

[32]C. Canal, D. Pastorino, G. Mestres, P. Schuler, M.-P. Ginebra, Relevance of microstructure for the early antibiotic release of fresh and pre-set calcium phosphate cements., Acta Biomater. 2013; 9; 8403-12.

[33] A Aguirre, A González, J. Planell, E. Engel, Extracellular calcium modulates in vitro bone marrow-derived Flk-1+CD34+ progenitor cell chemotaxis and differentiation through a calcium-sensing receptor., Biochem. Biophys. Res. Commun. 2010; 393; 156-61.

[34]A. Aguirre, J.A. Planell, E. Engel, Dynamics of bone marrow-derived endothelial 
progenitor cell/mesenchymal stem cell interaction in co-culture and its implications in angiogenesis, Biochem. Biophys. Res. Commun. 2010; 400; 284-291.

[35] J. Guillem-Marti, L. Delgado, M. Godoy-Gallardo, M. Pegueroles, M. Herrero, F.J. Gil, Fibroblast adhesion and activation onto micro-machined titanium surfaces, Clin. Oral Implants Res. 2013; 24; 770-780.

[36] E.B. Montufar, T. Traykova, J.A. Planell, M.P. Ginebra, Comparison of a low molecular weight and a macromolecular surfactant as foaming agents for injectable self setting hydroxyapatite foams: polysorbate 80 versus gelatine, Mater. Sci. Eng. C 2011;31:1498-504.

[37]A. Moshiri, A.M. Sharifi, A. Oryan, Role of Simvastatin on fracture healing and osteoporosis: a systematic review on in vivo investigations, Clin. Exp. Pharmacol. Physiol. 2016; 43; 659-684.

[38] S.R. Shah, C.A. Werlang, F.K. Kasper, A.G. Mikos, Novel applications of statins for bone regeneration, Natl. Sci. Rev. 2015; 2; 85-99.

[39] M.-P. Ginebra, E. Fernandez, F.C.M. Driessens, J.A. Planell, Modeling of the Hydrolysis of $\alpha$-Tricalcium Phosphate, J. Am. Ceram. Soc. 2004; 82; 2808-2812.

[40]T. Maeda, A. Matsunuma, T. Kawane, N. Horiuchi, Simvastatin promotes osteoblast differentiation and mineralization in MC3T3-E1 cells., Biochem. Biophys. Res. Commun. 2001; 280; 874-7.

[41]T. Maeda, T. Kawane, N. Horiuchi, Statins augment vascular endothelial growth factor expression in osteoblastic cells via inhibition of protein prenylation., Endocrinology. 2003;144; 681-92.

[42]T. Maeda, A. Matsunuma, I. Kurahashi, T. Yanagawa, H. Yoshida, N. Horiuchi, Induction of osteoblast differentiation indices by statins in MC3T3-E1 cells., J. Cell. Biochem. 2004;92; 458-71.

[43]H. Kaji, J. Naito, Y. Inoue, H. Sowa, T. Sugimoto, K. Chihara, Statin suppresses apoptosis in osteoblastic cells: role of transforming growth factor-beta-Smad3 pathway., Horm. Metab. Res. 2008;40; 746-51.

[44]Y. Qi, T. Zhao, W. Yan, K. Xu, Z. Shi, J. Wang, Mesenchymal stem cell sheet transplantation combined with locally released simvastatin enhances bone formation in a rat tibia osteotomy model, Cytotherapy. 2013;15 ; 44-56.

[45]K.H. Baek, W.Y. Lee, K.W. Oh, H.J. Tae, J.M. Lee, E.J. Lee, J.H. Han, M. Il Kang, 
B.Y. Cha, K.W. Lee, H.Y. Son, S.K. Kang, The Effect of Simvastatin on the Proliferation and Differentiation of Human Bone Marrow Stromal Cells, J. Korean Med. Sci. 2005; 20; 438.

[46] T. Maeda, A. Matsunuma, T. Kawane, N. Horiuchi, Simvastatin Promotes Osteoblast Differentiation and Mineralization in MC3T3-E1 Cells, Biochem. Biophys. Res. Commun. 2001; 280; 874-877.

[47] S. Ruiz-Gaspa, X. Nogues, A. Enjuanes, J.C. Monllau, J. Blanch, R. Carreras, L. Mellibovsky, D. Grinberg, S. Balcells, A. Díez-Perez, J. Pedro-Botet, Simvastatin and atorvastatin enhance gene expression of collagen type 1 and osteocalcin in primary human osteoblasts and MG-63 cultures, J. Cell. Biochem. 2007;101; 1430-1438.

[48]N. Ferrara, H.-P. Gerber, J. LeCouter, The biology of VEGF and its receptors, Nat. Med. 2003;9; 669-676.

[49]R.L. Kendall, K.A. Thomas, Inhibition of vascular endothelial cell growth factor activity by an endogenously encoded soluble receptor., Proc. Natl. Acad. Sci. U. S. A. 1993; 90; 10705-9.

[50] S. Hiratsuka, K. Nakamura, S. Iwai, M. Murakami, T. Itoh, H. Kijima, J.M. Shipley, R.M. Senior, M. Shibuya, MMP9 induction by vascular endothelial growth factor receptor-1 is involved in lung-specific metastasis., Cancer Cell. 2002; 2 ; 289-300.

[51]F. Shalaby, J. Rossant, T.P. Yamaguchi, M. Gertsenstein, X.-F. Wu, M.L. Breitman, A.C. Schuh, Failure of blood-island formation and vasculogenesis in Flk-1-deficient mice, Nature. 1995; 376; 62-66.

[52] R. Maas, C.-C. Huang, J.-S. Chen, T.-C. Wu, H.-B. Leu, P.-H. Huang, T.-T. Chang, S.J. Lin, J.-W. Chen, H. Yip, K. Kluge, B. Schäfer, D. Hossfeld, W. Fiedler, H. Drexler, A. Caruso, S. Kittner, D. Lackland, J. Lichtman, L. Lisabeth, D. Makuc, G. Marcus, A. Marelli, D. Matchar, C. Moy, D. Mozaffarian, M. Mussolino, G. Nichol, N. Paynter, E. Soliman, Pharmacotherapies and their influence on asymmetric dimethylargine (ADMA), Vasc. Med. 2005; 10; S49-S57.

[53]Y. Zhang, R. Zhang, Y. Li, G. He, D. Zhang, F. Zhang, Simvastatin augments the efficacy of therapeutic angiogenesis induced by bone marrow-derived mesenchymal stem cells in a murine model of hindlimb ischemia, Mol. Biol. Rep. 2012; 39; 285-293.

[54]M. Frick, J. Dulak, J. Cisowski, A. Józkowicz, R. Zwick, H. Alber, W. Dichtl, S.P. Schwarzacher, O. Pachinger, F. Weidinger, Statins differentially regulate vascular 
endothelial growth factor synthesis in endothelial and vascular smooth muscle cells, Atherosclerosis. 2003; 170; 229-236.

[55] A.T. Serajuddin, S.A. Ranadive, E.M. Mahoney, Relative lipophilicities, solubilities, and structure-pharmacological considerations of 3-hydroxy-3-methylglutaryl-coenzyme A (HMG-CoA) reductase inhibitors pravastatin, lovastatin, mevastatin, and simvastatin., J. Pharm. Sci. 1991; 80; 830-834.

[56] M. Bohner, J. Lemaître, P. Van Landuyt, P.Y. Zambelli, H.P. Merkle, B. Gander, Gentamicin-loaded hydraulic calcium phosphate bone cement as antibiotic delivery system., J. Pharm. Sci. 1997; 86; 565-72.

[57] A. Ratier, I. Gibson, S. Best, M. Freche, J. Lacout, F. Rodriguez, Setting characteristics and mechanical behaviour of a calcium phosphate bone cement containing tetracycline, Biomaterials. 2001; 22; 897-901.

[58] S. Gallinetti, C. Canal, M.-P. Ginebra, Development and Characterization of Biphasic Hydroxyapatite/ $\beta$-TCP Cements, J. Am. Ceram. Soc. 2014; 97; 1065-1073.

[59] G. Mestres, K. Kugiejko, D. Pastorino, J. Unosson, C. Öhman, M. Karlsson Ott, M.-P. Ginebra, C. Persson, Changes in the drug release pattern of fresh and set simvastatinloaded brushite cement, Mater. Sci. Eng. C. 2016; 58; 88-96.

[60] T. Haque, U. Mesbah, S. Talukder, K. Laila, M.S. Fatema, M. Islam, R. Selim, Model Dependent and Independent Approaches to Compare In vitro Release Profiles from Ethylcellulose and Eudragit L100 Based Matrix Tablets, J. Pharm. Sci. 2009; 8; 89-98.

[61] S. Basak, B. Jayakumar Reddy, K. Lucas Mani, Formulation and release behaviour of sustained release ambroxol hydrochloride HPMC matrix tablet, Indian J. Pharm. Sci. 2006; 68; 594.

[62] C. Canal, K. Khurana, S. Gallinetti, S. Bhatt, J. Pulpytel, F. Arefi-Khonsari, M.P. Ginebra, Design of calcium phosphate scaffolds with controlled simvastatin release by plasma polymerisation, Polym. 2016; 92; 170-178.

[63] S. Hayes, Remington: The Science and Practice of Pharmacy, volume I and volume II. Twenty-second edition, J. Med. Libr. Assoc. 2014; 102; 220-221.

[64] M. Montazerolghaem, K. Ott, Sustained release of Simvastatin from premixed injectable Calcium Phosphate Cement, J. Biomed. Mater. Res. A. 2013; 1-8.

[65] J. Chou, T. Ito, M. Otsuka, B. Ben-Nissan, B. Milthorpe, The effectiveness of the controlled release of simvastatin from $\beta$-TCP macrosphere in the treatment of OVX 
mice, J. Tissue Eng. Regen. Med. 2016; 10; E195-E203. 
Figure and Table Captions

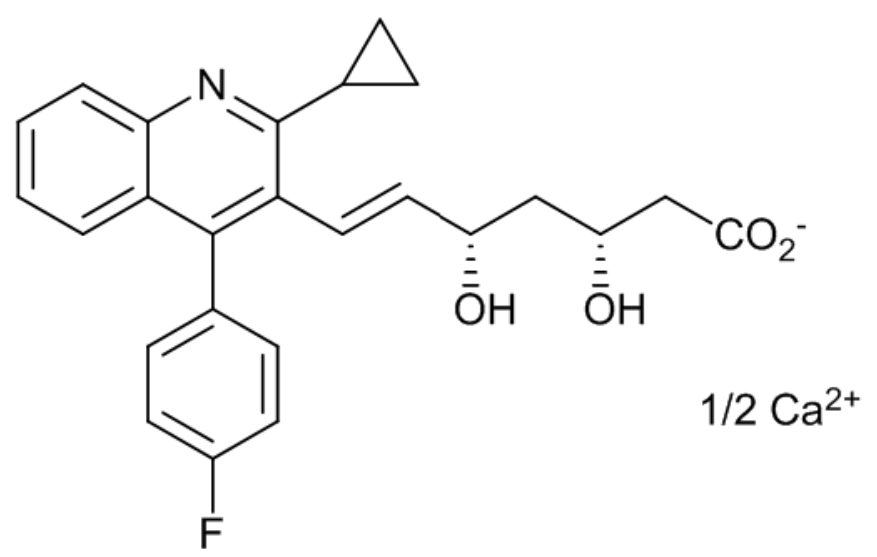

Figure 1. Chemical structure of the Pitavastatin used in this study. 

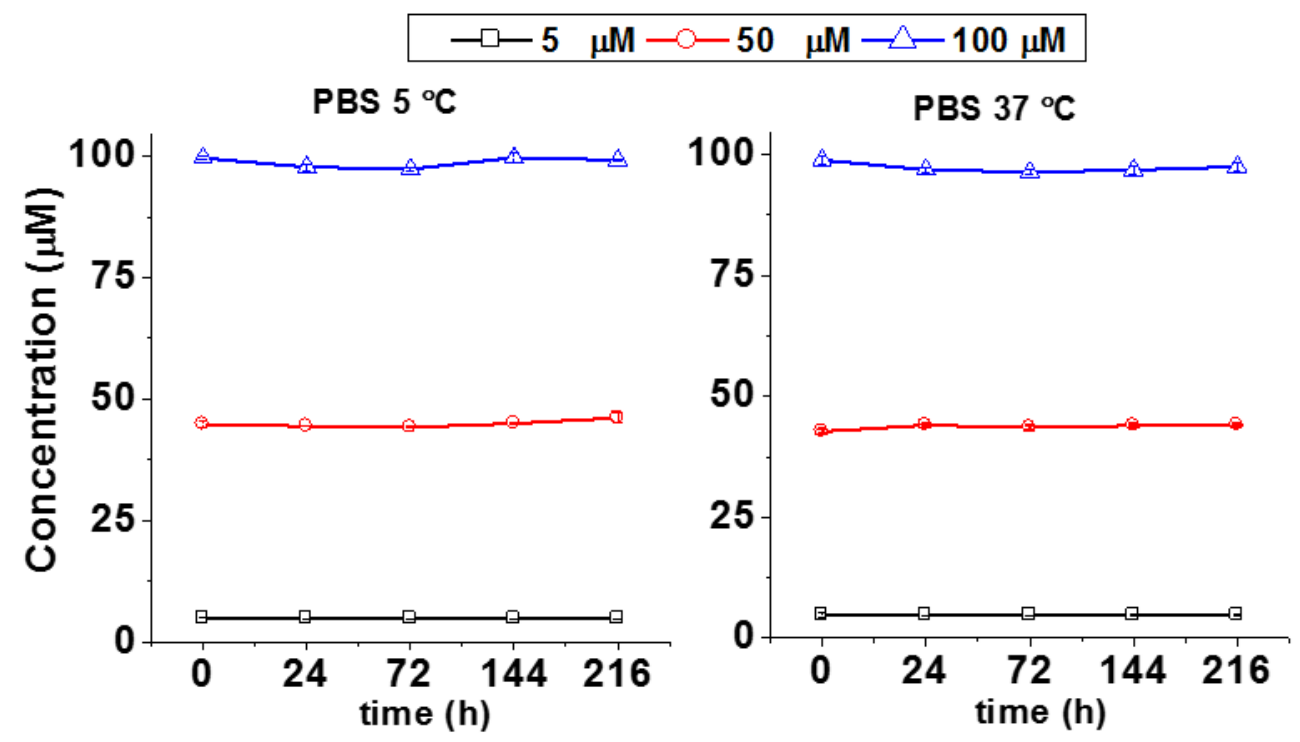

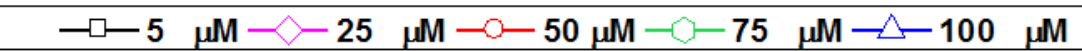
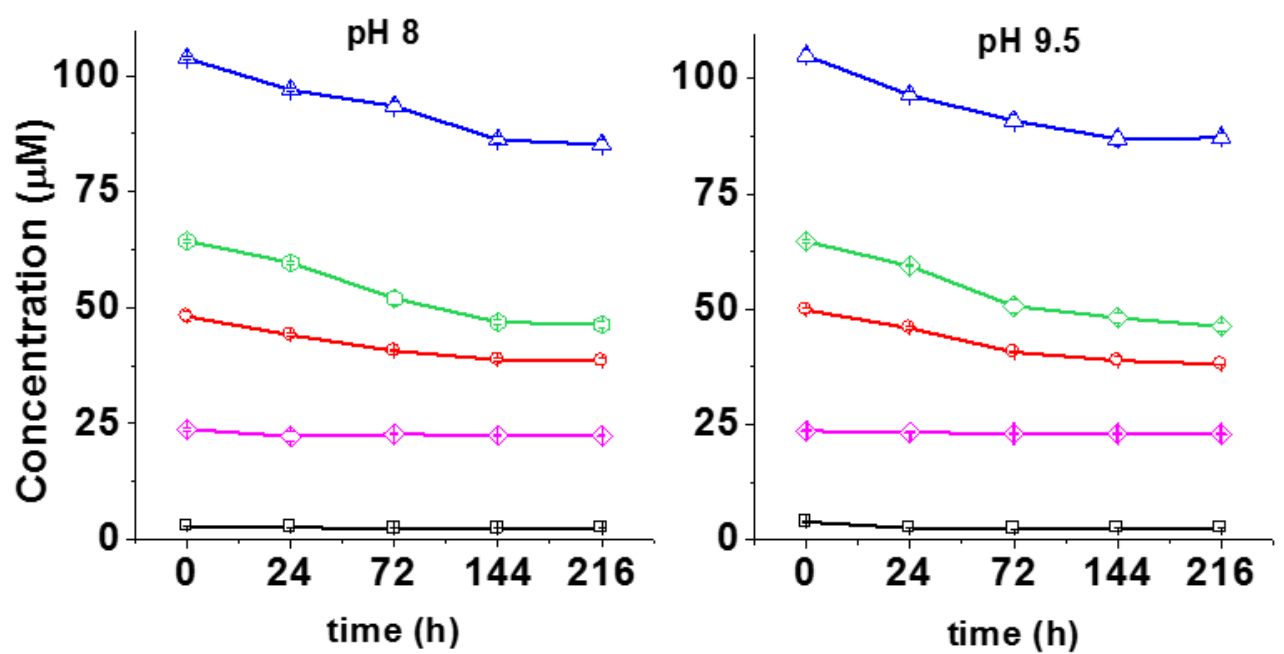

Figure 2. Influence of temperature ( 5 and $37^{\circ} \mathrm{C}$ ) (top) and $\mathrm{pH}\left(8\right.$ and 9.5) $\left(37^{\circ} \mathrm{C}\right)$ on the stability of PITA solutions at different concentrations (Standard deviation was calculated with three replicates, error bars are too small to be seen clearly). 


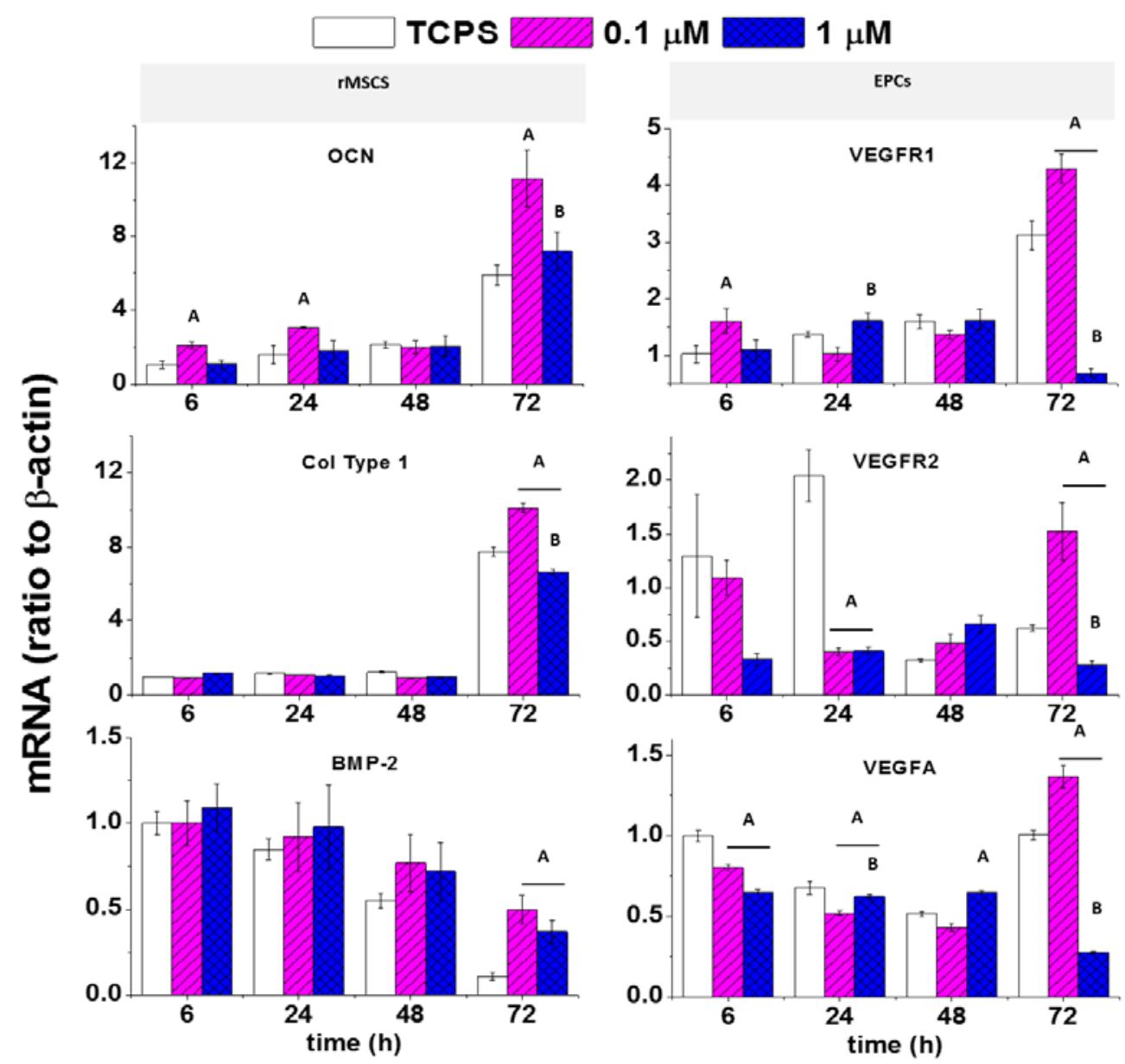

Figure 3. Influence of PITA on the gene expression of OCN, Col Type1, BMP-2 by rMSCs and VEGF-R1, VEGF-R2, VEGFA by EPCs and at 6, 24, 48 and $72 \mathrm{~h}$. The statistical difference with TCPS and $0.1 \mu \mathrm{M}$ are represented as A and B respectively for each time point $(\mathrm{P}<0.05)$. 

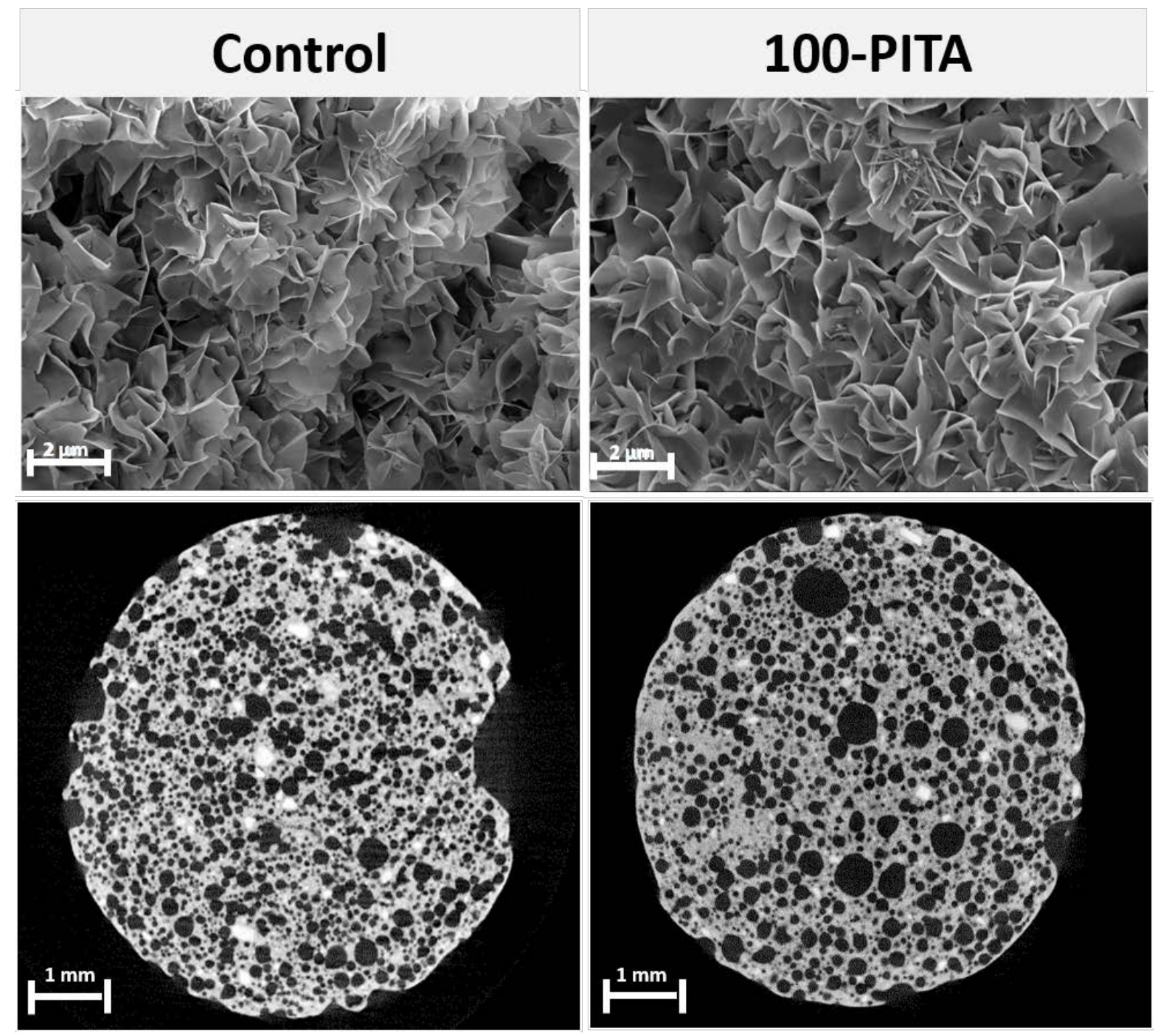

Figure 4. FESEM images of i-CPF of control and Pitavastatin loaded i-CPF with 100 $\mu \mathrm{M}$ h (top). $\mu \mathrm{CT}$ images of control i-CPF and Pitavastatin loaded i-CPF at $100 \mu \mathrm{M}$ (bottom). 


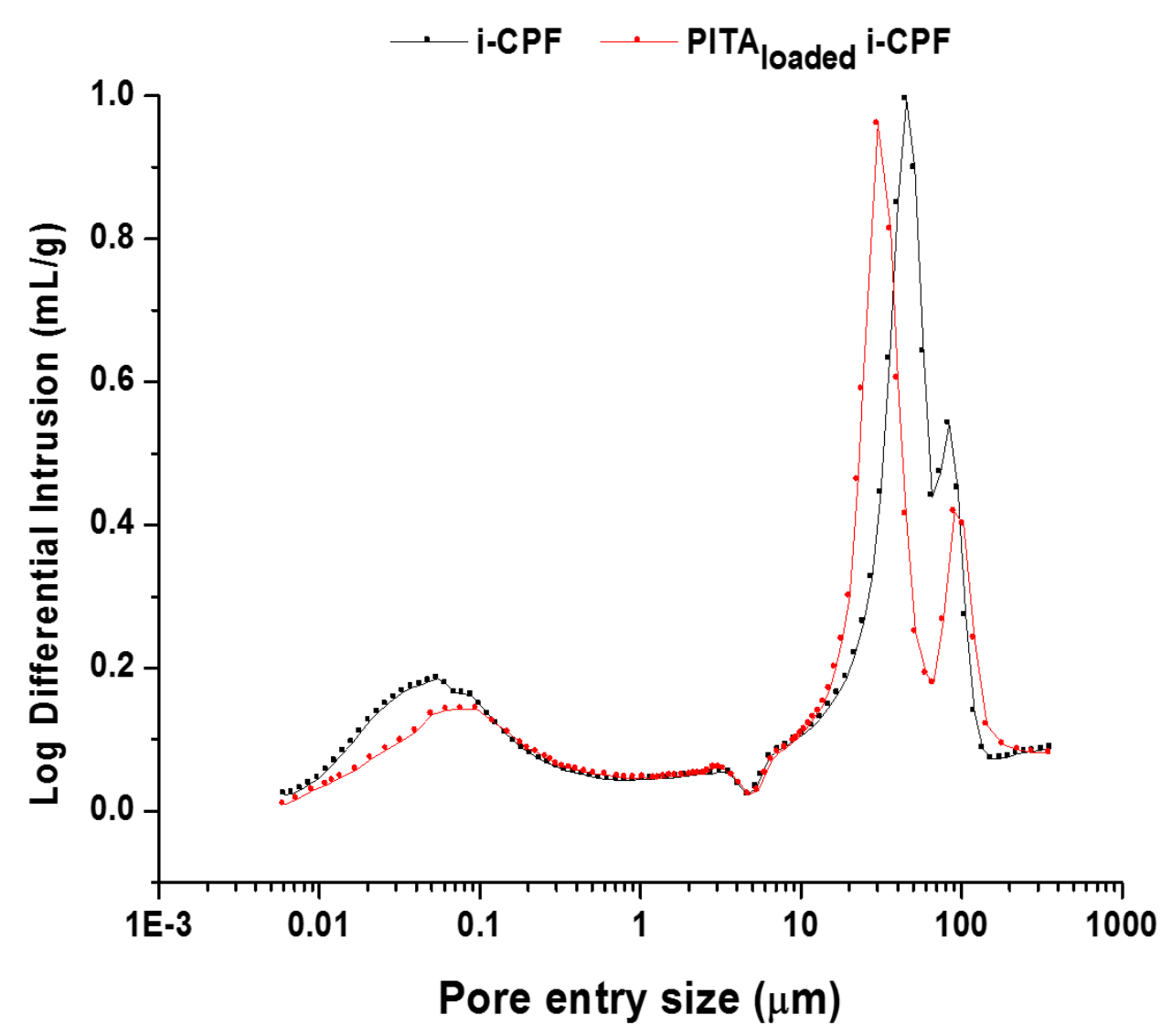

Figure 5. MIP pore size entry distribution $(n=4)$ of i-CPF and PITA loaded i-CPF. 


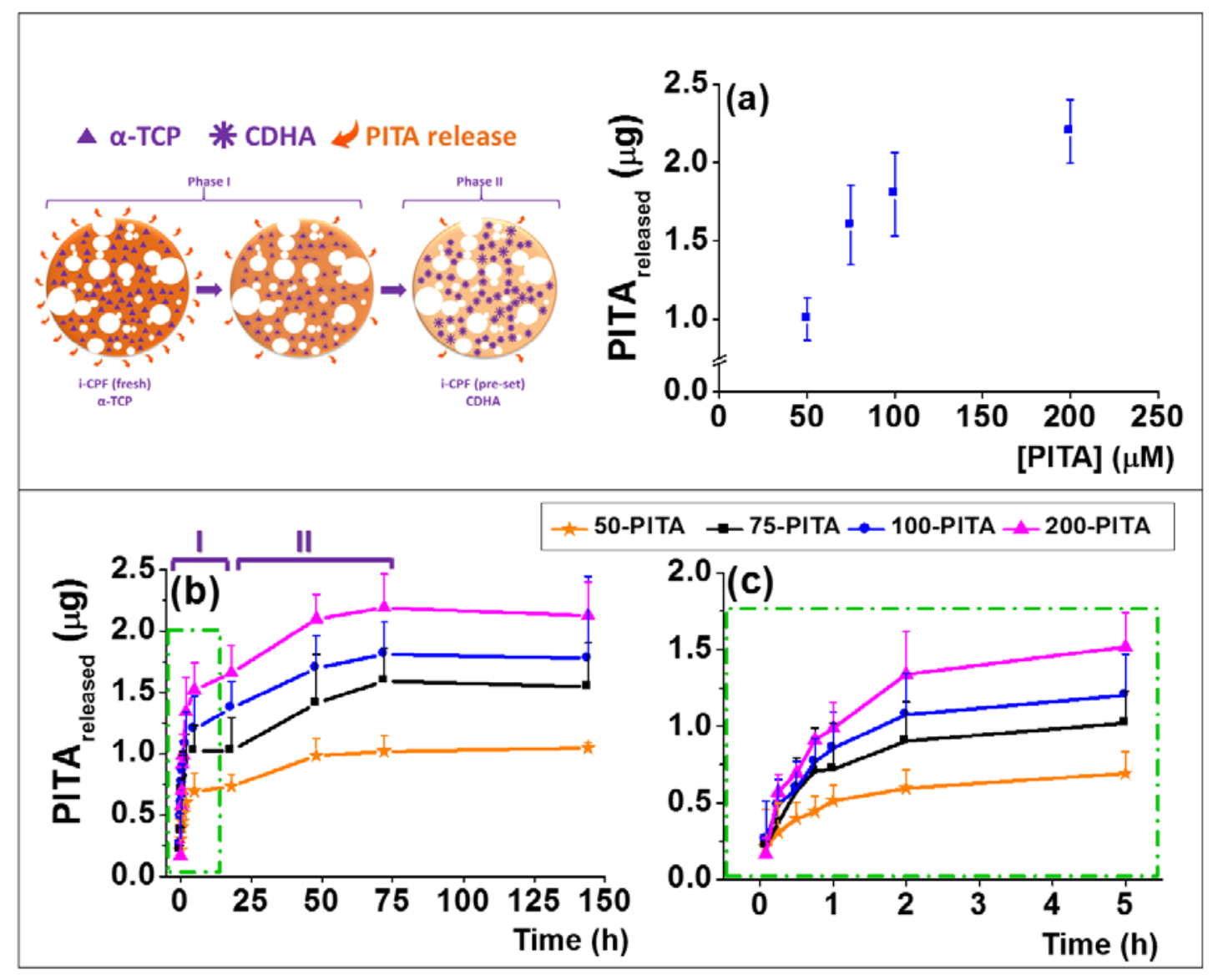

Figure 6. Total amount of PITA released at $72 \mathrm{~h}$ is plotted for each concentration of PITA loaded i-CPFs (a), and release curves of i-CPFs containing different amounts of PITA for 6 days (b), with zoom of the initial 5 hours (c). Proposed scheme of the release of PITA during the setting reaction (top left). 
Table 1: DNA sequences of forward (fw) and reverse (rv) primers for the selected genes used for real - time qPCR.

\begin{tabular}{|c|c|c|c|c|c|}
\hline $\begin{array}{l}\text { Related } \\
\text { Function }\end{array}$ & $\begin{array}{l}\text { Gene } \\
\text { Symbol }\end{array}$ & Gene Title & Primer sequences $\left(5^{\prime}-3^{\prime}\right)$ & Acc. No. & $\begin{array}{l}\text { Amplico } \\
\text { n size } \\
\text { (bp) }\end{array}$ \\
\hline Mineralization & OC & Osteocalcin & $\begin{array}{l}\text { CCAGGGGATCTGGGTAGG-fw } \\
\text { ATAGACTCCGGCGCTACCTC-rv }\end{array}$ & $\begin{array}{l}\text { NM_013414. } \\
1\end{array}$ & 63 \\
\hline $\begin{array}{l}\text { ECM } \\
\text { component }\end{array}$ & COL1 & Collagen-1 & $\begin{array}{l}\text { GCAGCTGACTTCAGGGATGT-fw } \\
\text { CATGTTCAGCTTTGTGGACCT-rv }\end{array}$ & $\begin{array}{l}\text { NM_053304. } \\
1\end{array}$ & 94 \\
\hline Differentiation & BMP-2 & $\begin{array}{l}\text { Bone } \\
\text { morphogenetic } \\
\text { protein } 2 \\
\end{array}$ & $\begin{array}{l}\text { CCCCTATATGCTCGACCTGT-fw } \\
\text { AAAGTTCCTCGATGGCTTCTT-rv }\end{array}$ & $\begin{array}{l}\text { NM_017178. } \\
1\end{array}$ & 137 \\
\hline \multirow[t]{4}{*}{$\begin{array}{l}\text { Vascularizatio } \\
\text { n }\end{array}$} & VEGFA & $\begin{array}{l}\text { Vascularization } \\
\text { endothelial } \\
\text { growth factor A }\end{array}$ & $\begin{array}{l}\text { CGGAGAGCAACGTCACTATG-fw } \\
\text { TGGTCTGCATTCACATCTGC-rv }\end{array}$ & $\begin{array}{l}\text { NM_031836. } \\
2\end{array}$ & 104 \\
\hline & $\begin{array}{l}\text { VEGFR } \\
-1\end{array}$ & $\begin{array}{l}\text { Vascularization } \\
\text { endothelial }\end{array}$ & $\begin{array}{l}\text { TGGAAAGCTCAGCGTACCTC-fw } \\
\text { AGTTAGAAGGAGCCAAAAGAGT } \\
\text { GT-rv }\end{array}$ & $\begin{array}{l}\text { NM_019306. } \\
1\end{array}$ & 113 \\
\hline & $\begin{array}{l}\text { VEGFR } \\
-2\end{array}$ & $\begin{array}{l}\text { growth factor } \\
\text { receptor-1 }\end{array}$ & $\begin{array}{l}\text { AAAGAGAGGGACTTTGGCCG-fw } \\
\text { GTCGCCACTTGACAAAACCC-rv }\end{array}$ & NM_013062. & 143 \\
\hline & & $\begin{array}{l}\text { Vascularization } \\
\text { endothelial } \\
\text { growth factor } \\
\text { receptor-2 }\end{array}$ & & 1 & \\
\hline House keeping & $\beta$-actin & Beta actin & $\begin{array}{l}\text { CCCGCGAGTACAACCTTCT -fw } \\
\text { CGTCATCCATGGCGAACT -rv }\end{array}$ & $\begin{array}{l}\text { NM_031144. } \\
2\end{array}$ & 72 \\
\hline
\end{tabular}

Table 2: Degradation of PITA at $\mathrm{pH} 8$ and $\mathrm{pH} 9.5$ with the function of time $(\mathrm{t}=24 \mathrm{~h})$ and total degradation when loaded in i-CPFs $24 \mathrm{~h}$, calculated according to eq. (2).

\begin{tabular}{|l|l|l|l|}
\hline & \multicolumn{2}{|c|}{ Degradation (\%) (t = 24h) } & $\begin{array}{l}\text { PITA degradation in i-CPFs } \\
\text { setting reaction (\%) (t = } \\
\text { 24h) }\end{array}$ \\
\hline & pH 8 & pH 9.5 & pH 9.5 $\rightarrow$ pH 7 \\
\hline $\mathbf{5} \boldsymbol{\mu M}$ & 0 & 0 & 0 \\
\hline $\mathbf{2 5} \boldsymbol{\mu M}$ & 0 & 0 & 0 \\
\hline $\mathbf{5 0} \boldsymbol{\mu M}$ & 8.29 & 7.84 & 8.00 \\
\hline $\mathbf{7 5} \boldsymbol{\mu M}$ & 7.26 & 6.59 & 6.83 \\
\hline $\mathbf{1 0 0} \boldsymbol{\mu M}$ & 8.19 & 8.17 & 8.17 \\
\hline
\end{tabular}

Table 3: Specific surface area (SSA), skeletal density and Porosity of i-CPFs without and with PITA at $100 \mu \mathrm{M}$. 


\begin{tabular}{lccc}
\hline \multicolumn{1}{c}{ Materials } & $\begin{array}{c}\text { Specific surface } \\
\text { area }\left(\mathbf{m}^{2} / \mathbf{g}\right)\end{array}$ & $\begin{array}{c}\text { Skeletal density } \\
\left(\mathbf{g} / \mathbf{c m}^{3}\right)\end{array}$ & Total porosity (\%) \\
\hline Control & 7.89 & 2.34 & $74.39 \pm 3.2$ \\
\hline $\mathbf{1 0 0 - P I T A}$ & 7.98 & 2.07 & $78.01 \pm 2.8$ \\
\hline
\end{tabular}

Table 4: Percentage of total release of PITA in each i-CPF specimen after $72 \mathrm{~h}$ and values of $\mathrm{R}^{2}$ and $\mathrm{n}$ with Korsmeyer-Peppas model for the release kinetics.

\begin{tabular}{cccc}
\hline i-CPFs & PITA released $(\%)$ & \multicolumn{2}{c}{ Korsmeyer-Peppas (KP) } \\
\cline { 3 - 4 } & & $\mathrm{n}$ & $\mathrm{R}^{2}$ \\
\hline 50 -PITA & $97.07 \pm 10.95$ & 0.29 & 0.9418 \\
\hline 75 -PITA & $97.02 \pm 17.81$ & 0.45 & 0.8813 \\
\hline 100 -PITA & $67.61 \pm 13.51$ & 0.32 & 0.8840 \\
\hline $200-$ PITA & $40.93 \pm 9.07$ & 0.20 & 0.9097 \\
\hline
\end{tabular}

